\title{
INVESTIGATION ON JULY 2012 INDIAN BLACKOUT
}

\section{LOI LEI LAI, HAO TIAN ZHANG1'A, CHUN SING LAI1'B, FANG YUAN XU1, SUKUMAR MISHRA2}

\author{
1State Grid Energy Research Institute, Beijing, China \\ ${ }^{2}$ Indian Institute of Technology Delhi, Delhi, India \\ AOn leave from City University London, UK \\ вOn leave from Brunel University, UK \\ EMAIL: xufangyuan@sgeri.sgcc.com.cn
}

\begin{abstract}
:
Twice Indian blackouts occurred at the end of July in 2012 left over 600 million of people in the dark for several hours. In these two-day, Indian grid disturbances were regarded as the most serious and large-scale blackout in the world in history. A report has been generated by the enquiry committee which was organized by the Ministry of Power, Government of India, to investigate the factors which led to the initiation of the grid disturbance. Recommendations were also generated by the committee in order to provide the plan for Indian grid enhancement. Further to the recommendations by Enquiry Committee, this paper will give further suggestions to minimize blackouts in future. An insight into decision support requirement for power network operation will be made.
\end{abstract}

\section{Keywords:}

Indian grid, blackout, decision support, strategic planning

\section{Introduction}

Three of the Indian grids were hit by power failure twice, leaving a huge disturbance in the country on 30th and $31 \mathrm{st}$ July 2012. The power outage affected 620 million people in India [1]. Trains were stopped, and a large number of passengers were stranded on the platform. Traffic congestion was in large cities including New Delhi and Kolkata due to traffic light problems. Government employers were told to go home as the Chief Minister claimed that power would be restored 10 to 12 hours later [2]. It was claimed that the Prime Minister of India, Manmohan Singh urgently attended the issue to attract $\$ 400$ million to invest on the grid and release the burden due to lack of electricity which is holding back economic growth [3]. Moreover, India will import electricity from Tala, Bhutan to relieve the pressure from heavy loading [4]. Government of India has agreed to support Bhutan to develop hydro power and will purchase no less than $10000 \mathrm{MW}$ of the power from Bhutan by 2020 [5].

Throughout the India grid history, Northern Region grid of Indian was collapsed on 2nd January, 2001. Power failure hit the Northern Region grid when officials claimed that a fault in the transmission system caused the darkness in the northern region [6, 7]. In 2012, the first blackout was occurring at around 2:35 am on 30th July in the Northern Region grid, which feeds electricity to 9 states of Northern India. Approximately $36000 \mathrm{MW}$ was affected in this blackout. Only $60 \%$ of load in Northern Region was restored by 11:00 am by means of hydroelectricity in the Northern Region and withdrawing power from Eastern and Western Regions. And the Northern Region grid was not supplied with the full load until 7:00 pm. Afterwards, on 31st July, there was another disturbance occurring at 1:00 pm, almost covering the entire power grid in India, including Northern Region, Eastern Region and Northeastern Region. Only some of the small areas were not affected, such as Narora. There were about $48000 \mathrm{MW}$ of the total loads affected in the second blackout, which was much more serious than the first one. It was reported that over 700 million people in India was suffered from darkness and manufacturing slowdown. Some important loads like hospital services were affected [6, 8]. As a matter of fact, the reasons for the collapsing of India power grid are not unique. Although Indian grid has its rule on a rational tariff structure on power supply [9], relay mal-operation and incorrect setting, high loading due to high temperature and high reactive power consumption in the circuit happened on several occasions over the past few years [10]. In accordance to CEA (Central Electricity Authority) of India, $27 \%$ of the power was lost in transmission or stolen so that the gap between peak supply and demand was maintained at $9 \%$ of the total capacity [11].

In 2011, power losses owing to transmission and distribution issues were approximately $23.7 \%$ on average in India, while the value was around $10-15 \%$ in Europe and North America [12]. A weak monsoon was blamed as lacking of rain and decelerating the hydro power generation [13]. In terms of India Meteorological Department, the actual rainfall in June, July and August in India were much less than expected normal rainfall in these three months in 2012 [12]. Furthermore, because of the price control on coal by Indian Government, some coal fire plants could not afford such expensive coal importation and left their power stations 
operating below capacity for their own interests [11]. Also, some experts blamed the disturbance due to the Indian grid infrastructure, which connects with both AC and DC transmission lines. The grids can exchange power with other region flexibly when only DC transmission cables connected between regions under normal operation. In addition, faults in one region are difficult to spread into others in abnormal conditions. Indian grid cannot take advantage from the benefits which bring security effects from only DC connection.

An Enquiry Committee had been founded to investigate the factors which led to the causes of the two grid disturbances on both days, and a report had been generated to investigate the situation and gave some critical recommendations [8]. One of the most serious problems was that the transmission system was very weak since the grid suffered from multiple outages. Besides, the Northern Region loads withdrew too much power from the Western Region grid so that the corridor linked between north and west was overloaded. Ineffective dispatch cannot prevent the Northern part from 'overload' electricity from the Western part. Without any fault occurring, zone 3 of the distance relay protecting the Bina-Gwalior link was tripped, and caused Western Region separated from Northern Region.

This paper will give a simulation to demonstrate and prove the reasons described above and a model with both HVDC and AC transmission lines was established in DIgSIELNT software Package [14] to find better solutions to improve the India grid security. Comparisons between grids with HVDC and grids with AC only will be made. Sensitivity analysis will be conducted to find out in what level, the generators in the Northern grid will be out of step when overdrawing power from the north.

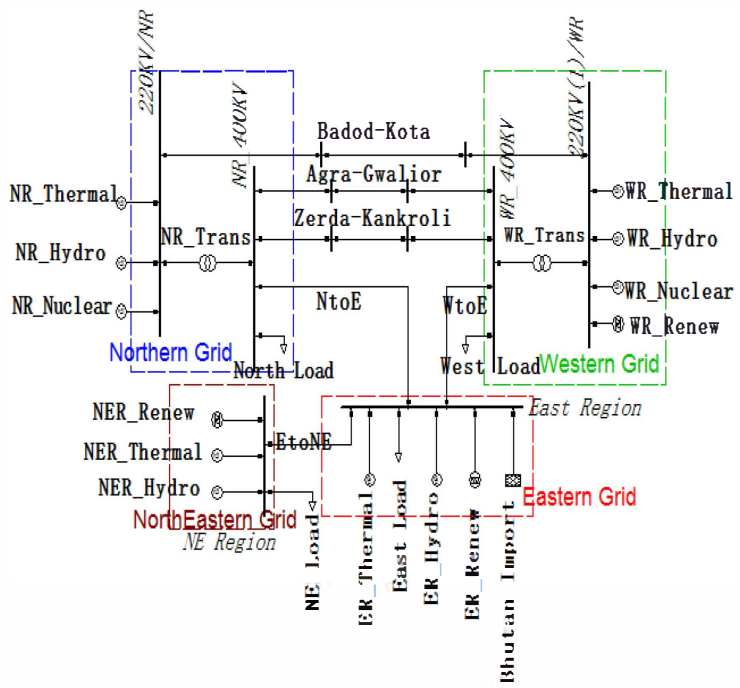

Figure 1. Brief Indian NEW grid for disturbance study

\section{Model development}

In this paper, a brief model was built for simulating the grid behavior during the disturbance with PowerFactory DIgSILENT software Package. As stated in the Enquiry Committee Report and some media, Northern Region grid imported energy from all the rest of NEW grid (Eastern Region, Western Region and Northeastern Region) before the disturbance occurrence. Besides, Bhutan, a country located at Northeast of India, also imported 1127 MW from the Eastern Region of Indian grid. The pre-disturbance generation and demand with power importing and exporting conditions on 30th July in 2012 02:00 am are shown in Table 1. It is worth noting that few lines had been tripped few hours before the collapse happening [15]. Each region in the NEW grid which was involved in the disturbance had been grouped by a general load and some generation types such as thermal, hydro, nuclear and renewables.

Figure 1 illustrates the India NEW grid model for analyzing the scenarios of the grid disturbance in DigS IELNT software package. The Northern Region and the Western Region were connected by both $400 \mathrm{kV}$ circuit lines from Agra to Gwalior and Zerda to Kankroli, and $220 \mathrm{kV}$ circuit lines from Badod to Kota. All lines were assumed to have the same parameters. Each region of these four in the simulation was modeled for hydro, thermal and renewables generations and one load. Eastern Region grid was connected to both Northern Region grid and Western Region grid by AC transmission line. Northeastern Region grid comprised of hydro, thermal and renewable generations which were connected to Eastern Region grid only.

TABLE 1. Generation and Demand Conditions With POWER IMPORT AND EXPORT BEFORE DISTURBANCES

\begin{tabular}{|l|c|c|c|}
\hline Region & $\begin{array}{c}\text { Generation } \\
\text { (MW) }\end{array}$ & $\begin{array}{c}\text { Demand } \\
\text { (MW) }\end{array}$ & $\begin{array}{c}\text { Import } \\
\text { (MW) }\end{array}$ \\
\hline Northern & 32636 & 38322 & 5686 \\
\hline Eastern & 12452 & 12213 & $\begin{array}{c}-239,(1127 \\
\text { MW to Bhutan) }\end{array}$ \\
\hline Western & 33024 & 28053 & -6229 \\
\hline Northeastern & 1367 & 1314 & -53 \\
\hline Total & 79479 & 79479 & \\
\hline
\end{tabular}

Table 2 illustrates the pre-disturbance generation power allocated in each region according to the enquiry report. The installed capacities of generations for each region were:

1. Northern Region:

19830 MW hydro generations, 34608 MW thermal generations $1620 \mathrm{MW}$ nuclear generations;

2. Eastern Region:

3882 MW hydro generations, 22545 MW thermal generations and $411 \mathrm{MW}$ from renewable energy sources;

3. Western Region: 
7448 MW hydro generations, 49402 MW thermal generations, $1840 \mathrm{MW}$ nuclear generation and 7909.95 MW from renewable energy sources;

4. Northeastern Region:

$1200 \mathrm{MW}$ hydro generations, 2454.94 MW thermal generations and $228 \mathrm{MW}$ from renewable energy sources

TABLE 2. GENERATION POWER AlLOCATION IN EACH REgiON

\begin{tabular}{|c|c|c|c|c|}
\hline Regions & North & Northeast & East & West \\
\hline Hydro & $10000 \mathrm{MW}$ & $267 \mathrm{MW}$ & $2000 \mathrm{MW}$ & $6000 \mathrm{MW}$ \\
\hline Thermal & $21636 \mathrm{MW}$ & $1000 \mathrm{MW}$ & $10200 \mathrm{MW}$ & $24024 \mathrm{MW}$ \\
\hline Nuclear & $1000 \mathrm{MW}$ & - & - & $1400 \mathrm{MW}$ \\
\hline Renewable & - & $100 \mathrm{MW}$ & $252 \mathrm{MW}$ & $600 \mathrm{MW}$ \\
\hline Total & $32636 \mathrm{MW}$ & $1367 \mathrm{MW}$ & $12452 \mathrm{MW}$ & $33024 \mathrm{MW}$ \\
\hline
\end{tabular}

\section{Case Study}

\section{Case 1. Load changes in the Northern Region}

As can be seen in the Enquiry Committee report, load in the Northern Region were larger than power generated, which means the Northern Region needs to import power from other regions unless there is a load shedding in the Northern Region. Besides, automatic voltage regulator (AVR) in the India grid could control the voltage level for some degrees. In this case, a sensitivity analysis was carried out to find out at what level the generators in Northern Region grid will have pole slipping with the Western Region. Another important task is to make a comparison between grids with AVR inside generators and without AVR.

\section{A. Sensitivity analysis}

The aim of the sensitivity analysis is to find out at what level the increased load will lead to generators in Northern Region out of step with the rest of the NEW grid. The increased level of reactive power of the load in the Northern Region is fixed at $5 \%$. The increased level of active power is changed from $1 \%$ to $5 \%$ with a step size of $0.5 \%$, with minimum and maximum value of frequency in the Northern Region and Western Region recorded in Table 3. Pole slip had been pointed out in the table that when Northern Region grid active power was increased by $3.5 \%$ and reactive power was increased by $5 \%$, generators in the Northern Region were out of step. Gaps between maximum and minimum value for both Northern Region and Western Region grid frequency were getting larger in terms of the increased Northern Region load.
TABLE 3. RESUlTS OF SENSITIVITY ANALYSIS FOR LOAD INCREASED IN NORTHERN REGION

\begin{tabular}{|c|c|c|c|c|c|}
\hline \multirow{2}{*}{$\begin{array}{c}\text { Freque } \\
\text { ncy }\end{array}$} & \multicolumn{2}{|c|}{$\begin{array}{c}\text { Frequency in the } \\
\text { Northern Region } \\
\text { grid }\end{array}$} & \multicolumn{2}{c|}{$\begin{array}{c}\text { Frequency in the } \\
\text { Western Region grid }\end{array}$} & \begin{tabular}{c} 
Pole \\
Slip \\
\cline { 2 - 6 } \\
Increased \\
by \%
\end{tabular} \\
\cline { 2 - 6 }
\end{tabular}

\section{B. Applying AVR into the grid}

The role of the Automatic Voltage Regulator is to control the magnitude of the terminal voltage of the generators. In the next scenario, typical AVRs for 1981 IEEE Type ST1 Excitation System [14] had been added into the generators in the grid. Figures 2 demonstrated the grid behaviors on increasing Northern Region load by $3.5 \%$ for both active and reactive power when the grid had no AVRs, while Figure 3 demonstrated the grid behaviors on increasing Northern Region load by $5 \%$ for both active and reactive power when the grid had AVRs . It is not very difficult to find out that the generators of the Northern Region in the grid with AVRs were not out of step with the rest of the regions, whereas the generators without AVRs had pole slipping when the load was changed only by $3.5 \%$. After the Northern Region grid increased the load, the grid with AVRs could still operate, with the frequency stabilized at $49.97 \mathrm{~Hz}$. The grid with AVRs was much more stable than the one without AVRs. 


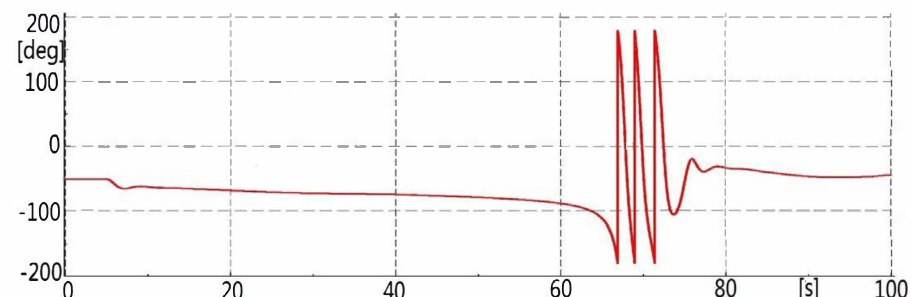

(a)

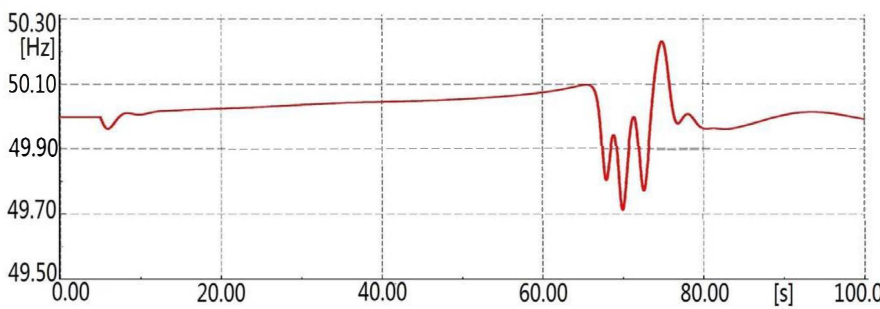

(b)

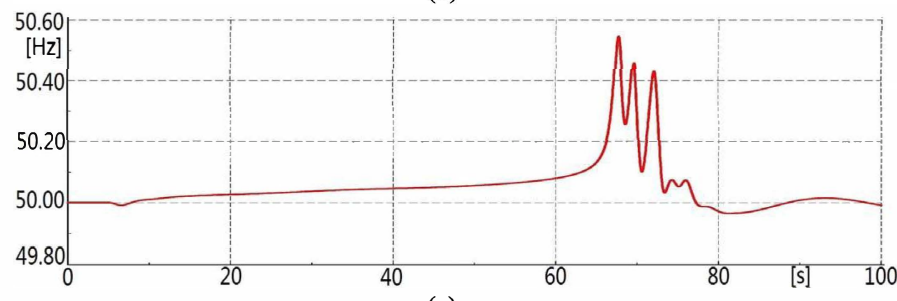

(c)

Figure 2. The grid behavior ((a)Rotor angle of the Northern Region thermal, (b)Northern Region Frequency, (c)Western Region Frequency) on increasing Northern Region load by $3.5 \%$ in both active and reactive power when grid without AVRs

Case 2. Comparisons between models with HVDC only, $H V A C$ only and model with both DC and AC connected

In this case, the impacts from HVDC had been considered to give recommendations on grid enhancement and expansion. $500 \mathrm{kV}$ CIGRE HVDCs were connected to the system between each region. Short-circuit events are simulated for models with HVDC only, AC transmission lines only and models with both HVDC and AC transmission lines. Load events on Northern Region grid are emulated on models as well in order to compare among the models.

\section{A. Short-circuit events}

Short circuit event occurred in the Northern Region grid, had been considered in this case. A 3-phase short-circuit fault was considered. It had a resistance of $0.1 \Omega$ and reactance of $1 \Omega$ at $3 \mathrm{sec}$ and the fault was cleared after $0.15 \mathrm{sec}$. Changes in frequency at the Northern Region and Western Region had been observed. As seen in Figures 4 (a) and (b), the grid was connected by ac transmission line, the frequency in the Northern Region was increased by $0.24 \mathrm{~Hz}$ since the fault occurred in the Northern Region. After few seconds, the frequency in the Northern Region was stabilized at $50 \mathrm{~Hz}$ as the fault had been cleared after $0.15 \mathrm{~s}$. Because of the distance between north and west, the impact by the fault occurred in the Northern Region was much smaller than that in the Western Region. The frequency was only increased by $0.05 \mathrm{~Hz}$, and after about 10 seconds, it recovered back to 50 $\mathrm{Hz}$.

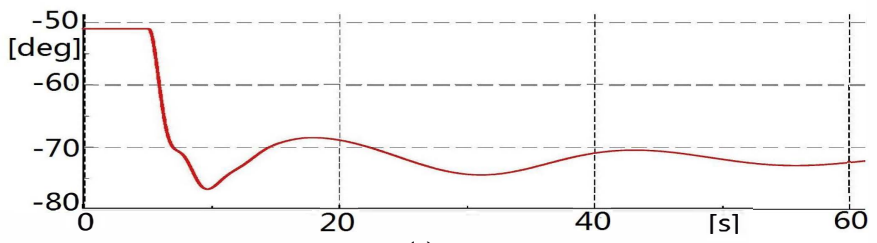

(a)

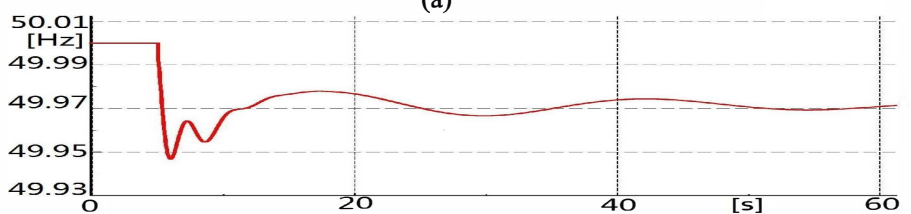

(b)

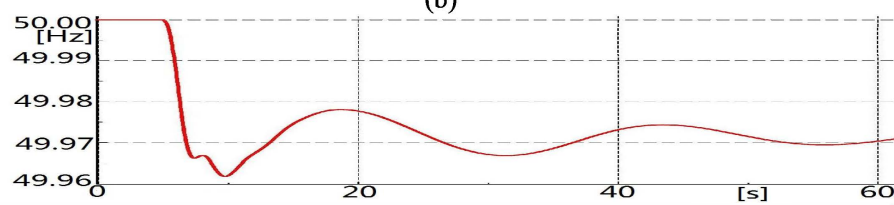

(c)

Figure 3. The grid behavior ((a)Rotor angle of the Northern Region thermal, (b)Northern Region Frequency, (c)Western Region Frequency) on increasing Northern Region load by $5 \%$ in both active and reactive power when grid with AVRs

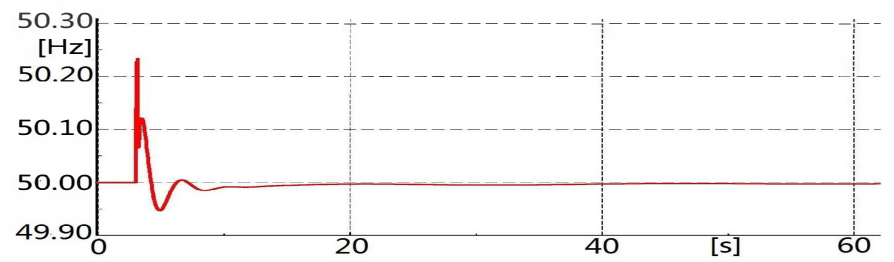

(a)

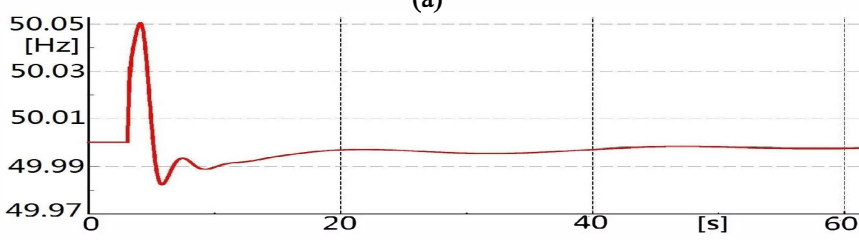

(b)

Figure 4. Frequency changes at (a) Northern Region and (b) Western Region when 3-phase short-circuit fault occurred in Northern Region of the grid with only AC transmission connection

The same scenario had been simulated in the grid with regions connected by $500 \mathrm{kV}$ HVDCs, with the results of the frequency changes demonstrated in Figures 5 (a) and (b). In Figure 5 (a), the frequency in Northern Region dropped under 
49.5 Hz. After around 90 seconds the frequency in the Northern Region only recovered back to $49.86 \mathrm{~Hz}$. However, for the Western Region, from Figure 5 (b), the frequency was increased to $50.88 \mathrm{~Hz}$ and remained on a new level owing to the isolation of the HVDCs. Also, a model with both HVDC and $\mathrm{AC}$ transmission lines were compared to the models with HVDC only and AC transmission lines only. A CIGRE 500 $\mathrm{kV}$ HVDC model was applied between the Western and Northern Region to replace two of the seven parallel AC transmission lines as shown in Figure 1, which were supplying $1063 \mathrm{MW}$ power before the disturbance occurred. Frequency changes at Northern Region and Western Region when 3-Phase short-circuit fault occurred in Northern Region of the grid were depicted in Figures 6 (a) and (b). In Figure 6, the frequency in Western Region grid still recovered back to $50 \mathrm{~Hz}$ because of the $\mathrm{AC}$ connections.

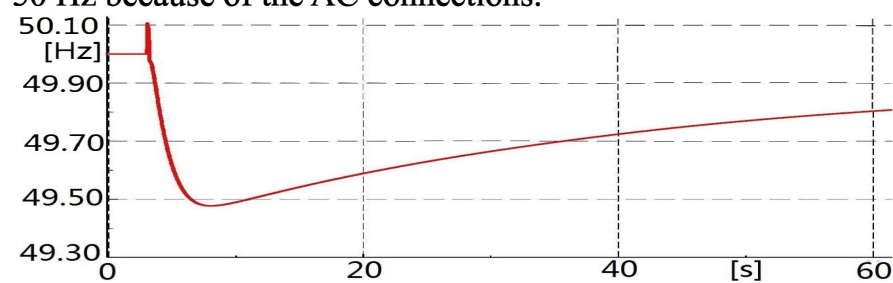

(a)

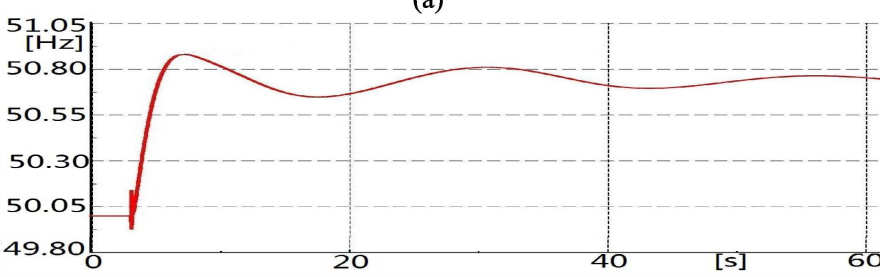

(b)

Figure 5. Frequency changes at (a) Northern Region and (b) Western Region when 3-phase short-circuit fault occurred in Northern Region of the grid with HVDC connection

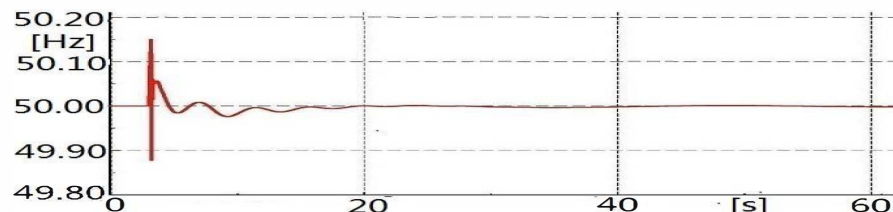

(a)

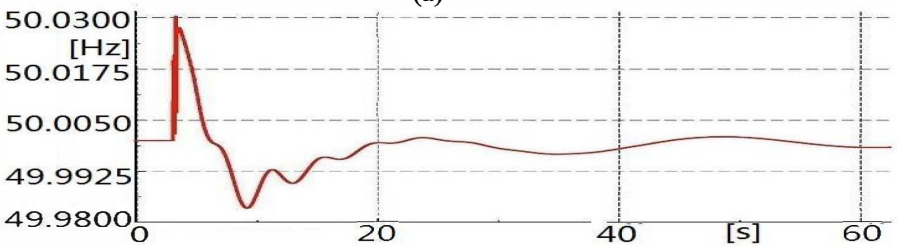

(b)

Figure 6. Frequency changes at (a) Northern Region and (b) Western Region when 3-phase short-circuit fault occurred in Northern Region of the grid with both HVDC and HVAC connection between Northern Region and Western Region

\section{B. Effects due to load change}

The Northern Region load was increased by $5 \%$ for both reactive and active power in both $\mathrm{AC}$ models and HVDC models at $5 \mathrm{sec}$. As discussed in case 1, the generators in the Northern Region had pole slipping. Figures 7 (a) and (b) illustrated the behavior of the Northern and Western Region frequency in the AC models. The frequency of the grid with HVDCs was shown in Figures 8 (a) and (b). The generators in the Northern Region were out of step with the rest regions in the grid. The difference between the frequency behaviors in the two models was that the frequency in the Western Region did not change too much. Security of the grid had been improved by applying HVDCs between regions. While in Figures 9 (a) and (b), which showed that the effects in frequency when Northern Region load increased in grid with both HVDC and AC transmission connected, the fluctuations of the frequency in both Northern and Western Region were much stronger than in Figure 7, though both Figures were indicated that Generators in Northern Region were out of step from the rest of the grid. Furthermore, the systems were collapsed after $45 \mathrm{sec}$.

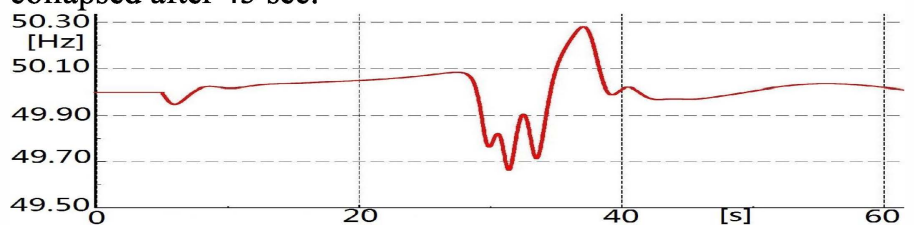

(a)

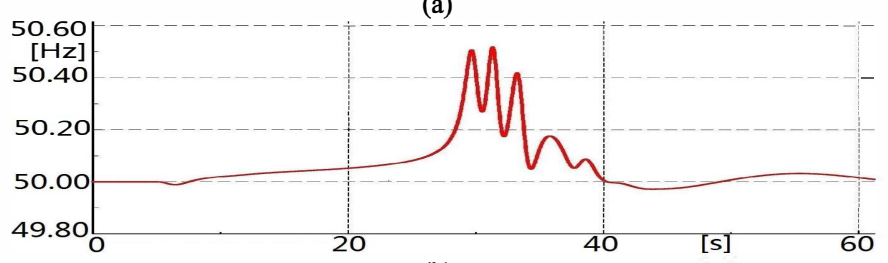

(b)

Figure 7. Frequency changes at (a) Northern Region and (b) Western Region with only AC transmission connection when northern load increased in both of active and reactive power by $5 \%$

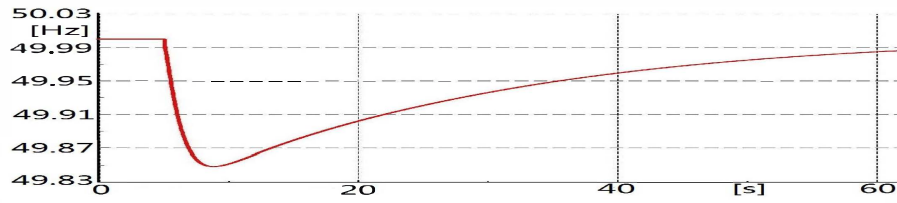

(a)

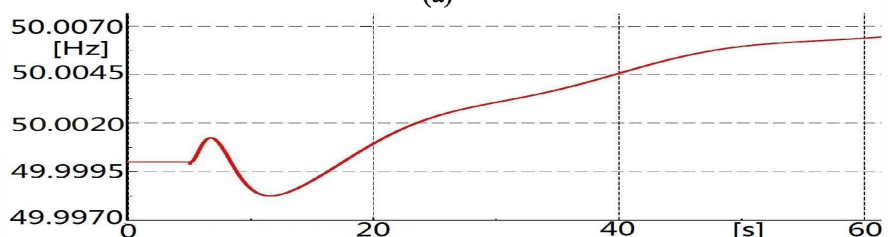

(b)

Figure 8. Frequency changes at (a) Northern Region and (b) Western Region with only HVDC transmission connection when northern load increased in both of active and reactive power by $5 \%$ 


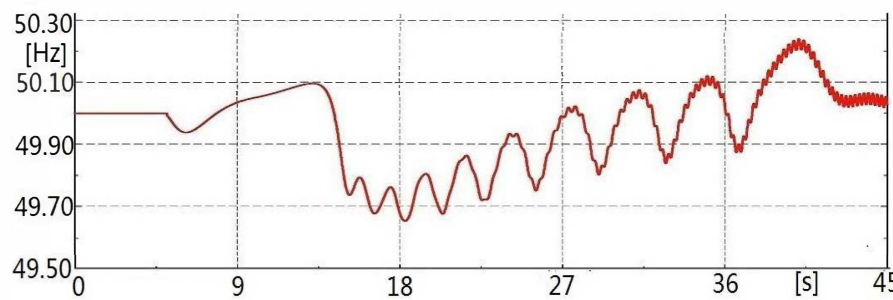

(a)

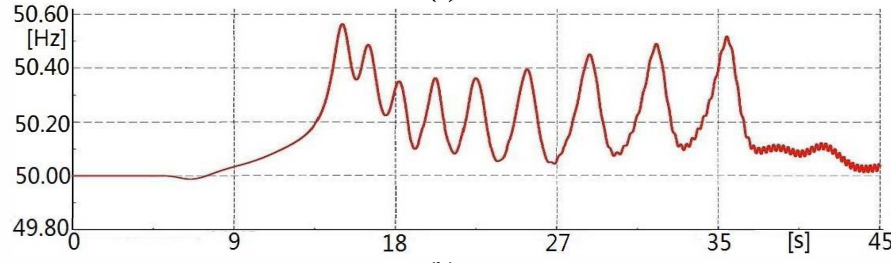

(b)

Figure 9. Frequency changes at (a) Northern Region and (b) Western Region with both HVDC and AC transmission connection when Northern Region load increased in both of active and reactive power by $5 \%$

\section{Conclusions}

This paper discussed the reasons for the blackout occurred on $30^{\text {th }}$ and $31^{\text {st }}$ July 2012 . The problem for the Indian grid applying both HVDC and AC transmission line had been investigated. Scenarios on grid with and without Automatic Voltage Regulator (AVR) had been simulated with a brief model established in DIgSILENT Software Package. Different grid behavior between using HVDC and AC transmission line during Northern Region had been discussed. This paper is not dealing with reliability. However, the authors look forward to some publications along this line. Naturally, the inclusion of capacitor banks and SVCs at key substations will be required. Frequency variation is an important indicator for the system security assessment. In this paper the frequency performance gave a good indication for the system stability. Sensitivity analysis on Northern and Western Region frequency had been considered to investigate the load level in the Northern Region where pole slipping would occur. Based on the simulation, some recommendations will be made to the India grid. Firstly, applying AVRs inside the generators could make the system more stable. Secondly, HVDC and HVAC need to be coordinated properly to minimize power system instability. HVDC should mainly be focused for electricity transmission while HVAC for interconnection use. This paper has given an insight into decision support requirement for power network operation and will make a contribution to practical design for modern power grid.

\section{References}

[1] http://www.usatoday.com/news/world/story/2012-07-31 /india-power-outage/56600520/1, visited on 16th Aug, 2012

[2] http://www.guardian.co.uk/world/2012/jul/31/india-blac k out-electricity-power-cuts, visited on 16th Aug, 2012

[3] http://washpost.bloomberg.com/Story?docId=1376-M7 YDKA0YHQ0X01-79TK1GQCDQF2C5AQ5A383U7 GQR, visited on 16th Aug, 2012

[4] http://www.thehindubusinessline.in/2006/08/17/stories/ 2006081704790100.htm, visited on 16th Aug, 2012

[5] http://www.indianembassythimphu.bt/mega.html, visited on 16th Aug, 2012

[6] http://www.thehindu.com/news/national/article3702075. ece?homepage $=$ true, visited on 20th Oct, 2012

[7] http://news.bbc.co.uk/1/hi/world/south_asia/1096957.st $\mathrm{m}$, visited on 20th Oct, 2012

[8] "Report of the Enquiry Committee on Grid Disturbance in Northern Region on 30th July 2012 and in Northern, Eastern \& North-eastern Region on 31st July 2012”, http://www.cea.nic.in/reports/articles/god/grid_disturba nce_report.pdf, visited on 16th Aug, 2012

[9] " $\mathrm{ABC}$ of $\mathrm{ABT}, \mathrm{A}$ Primer on Availability Tariff", http://www.nldc.in/docs/abc_abt.pdf, visited on 16th Aug, 2012

[10] "Loading of Extra High Voltage (EHV) transmission elements on the network and its impact on the grid security",http://www.nrldc.in/flasher/Website_NLDC_T TC_calculations_SIL01Aug2012.pdf , [online] visited on $\overline{1}$ st Sept, $201 \overline{2}$

[11] http://www.bloomberg.com/news/2012-08-01/worst-ind ia-outage-highlights-60-years-of-missed-targets-energy. $\mathrm{Ht}$ ml, visited on 20h Oct, 2012

[12] GlobalData, "July 2012 Power Blackout in Northern India - Undisciplined State Electricity Boards and Technology Shortcomings to Blame" Reference Code: GDSG0053VPT

[13] http://spectrum.ieee.org/energywise/energy/the-smartergrid/disappointing-monsoon-season-wreaks-havoc-withindias-grid, visited on16th Aug, 2012

[14] PowerFactory, DIgSILENT 14.1

[15] “Operation Performance Report for the Month of July 2012", http://www.nldc.in/NLDC/monthlyreport/July\%20 $2012 \% 20$ Monthly\%20Report\%20.pdf, visited on 16 th Aug, 2012 